\title{
Yapıştırıcı ile Birleştirilmiş Mil-Göbek Bağlantılarında Lineer-Elastik Gerilme Analizi ve Göbek Kenar Geometrisinin Dayanıma Etkisinin Araştırılması
}

\author{
İsmail SARAÇ \\ Aksaray Üniversitesi, Mühendislik Fakültesi, Makina Mühendisliği Bölümü. 68100 Aksaray, Türkiye \\ ismailsarac@aksaray.edu.tr \\ Received/Geliş:02.04.2020 \\ Accepted/Kabul: 09.06.2020
}

Öz: Yapıştırma bağlantılarının kullanım alanı, klasik birleştirme yöntemlerine göre sağladığı avantajlardan dolayı giderek artmaktadır. Ancak, özellikle bindirme uzunluğunun uç bölgelerinde oluşan gerilme yığılmaları çatlak başlangıcı ve ilerlemesine neden olarak bağlantıların hasar görmesini sağlamaktadır. Araştırmacılar tarafından tek tesirli yapıştırma bağlantılarında yapılan çalışmalar incelendiğinde, bindirme bölgesi uç kısımlarında yapılan değişikliklerin bağlantı performansını etkilediği görülmektedir. Silindirik yapıştırma bağlantılarıyla ilgili yapılan çalışmalarda ise genellikle bağlantıların çekme yükü altındaki performansları araştırılmıştır. Bu çalışmada, ilk olarak bir silindirik yapıştırma bağlantısı olarak tasarlanan mil-göbek bağlantı modelinin burulma momenti altındaki lineer elastik gerilme analizi ANSYS APDL programı kullanılarak yapılmıştır. Daha sonra, oluşturulan yeni mil-göbek bağlantı modellerinde göbek kenarlarında yapılan tasarım değişikliklerinin bağlantı performansına etkileri, yapılan gerilme ve hasar analizleriyle araştırılmıştır. Oluşturulan silindirik yapıştırma bağlantısı modellerine burulma momenti uygulanmasının sebebi makinelerde mil-göbek bağlantılarının döndürme momenti aktarımında kullanılmasıdır. Yapılan hasar analizleri sonucunda göbek kenar çapında yapılan malzeme azaltılmasının kritik bölge olan mil yapıştıııı tabakası ara yüzeyleri uç bölgelerindeki gerilme yığılmalarını azaltarak yapıştırma bölgesindeki hasar mukavemetini arttırdığı tespit edilmiştir. En fazla mukavemet artışı göbek dış çapı 6 mm' ye düşürülen Model-4 tasarımında \%30 olarak gerçekleşmiştir. Buna karşın oluşturulan yeni modellerde göbek hasar mukavemeti azalırken mil hasar mukavemeti değişmemiştir. Bu çalışma şartlarında ideal modelin göbek dış çapı $7 \mathrm{~mm}$ olan Model-3 tasarımı olduğu tespit edilmiştir.

Anahtar Kelimeler: Mil göbek bağlantısı, hasar analizi, yapıştırma bağlantısı

\section{Linear-Elastic Stress Analysis and Investigation of the Effect of Hub Edge Geometry on Strength in Shaft-Hub Connections Combined with Adhesive}

\begin{abstract}
The area of application of adhesive joints is gradually increasing due to the advantages which provided compared to conventional joining methods. However, especially the stress concentration on the edges of the adhesion zone causes crack initiation and progression, causing failure to the joints. When the studies carried out by the researchers on the single lap adhesive joints are examined, it is seen that the changes in the overlap end geometries affect the joint performance. In studies on cylindrical bonding joints, the performances of the joints under tensile load were generally investigated. In this study, the linear elastic stress analysis under the torsional moment of the shaft-hub connection model, which was originally designed as a cylindrical bonding joint, was performed using ANSYS APDL finite element analysis program. Then, the effects of design changes on the edges of the hub in the new shaft-hub connection models created were investigated by stress and failure analysis. The reason for the torsional moment applied to the cylindrical bonding models created is that the shafthub connections are used for torque transfer in machines. As a result of the failure analysis, it has been determined that the reduction of the material at the hub edge increases the failure strength in the adhesion region by reducing the stress concentrations at the edge of the shaft adhesive layer interfaces which is the critical region. The highest strength increase was 30\% in Model-4. However, in the new models created, the hub failure strength decreased, and the shaft failure strength did not change. In these working conditions, it was determined that the ideal model was the Model-3 design.
\end{abstract}

Keywords: Shaft hub connection, failure analysis, adhesive joints

Saraç I.., "Yapıștırıcı ile Birleştirilmiş Mil-Göbek Bağlantılarında Lineer-Elastik Gerilme Analizi ve Göbek Kenar Geometrisinin Dayanıma Etkisinin Araştırılması" El-Cezerî Fen ve Mühendislik Dergisi 2020, 7(3); 994-1007. 


\section{Giriş}

Bağlantı elemanı olarak yapıştırıcıların kullanılması, cıvata, kaynak, perçin, sıkı geçme ve lehim gibi konvansiyonel bağlantı elemanlarının yanında, yapıştırıcı teknolojisindeki ilerlemelere paralel olarak giderek artmaktadır. Yapıştırma bağlantılarının diğer bağlantı çeşitleriyle karşılaştırıldığında, farklı özelliklerdeki malzemeleri birleştirme, birleştirme bölgesinde daha homojen bir gerilme dağılımı, bağlantılarda birleştirmenin yanı sıra sızdırmazlık özelliğinin olması, yorulma özelliklerinin iyi olması ve sistemleri daha hafif hale getirmesi gibi önemli avantajları bulunmaktadır. Birleştirme elemanı olarak yapıştırıcılar, enerji verimliliğinin önemli olduğu havacılık ve otomotiv endüstrisinde cıvatalı ve perçinli birleştirme yöntemlerine göre sağladığı daha hafif yapılar nedeniyle yoğun olarak kullanılmaya başlanmıştır. Bütün bu üstünlüklerinin yanında yapıştırma bağlantılarının dayanımını etkileyen çok sayıda faktör bulunduğu için yapıştırma bağlantılarında klasik bağlantı yöntemlerine göre bağlantı mukavemeti hakkında kesin bir şey söylemek zordur. Dolayısıyla yapıştırma bağlantıları birçok araştırmacının ilgisini çekmektedir. Yapıştırma bağlantılarının performansını etkileyen faktörlerden birisi de bağlantı tasarımıdır. Literatür incelendiğinde üzerinde en çok araştırma yapılan bağlantı tipi tek tesirli bindirme bağlantılarıdır. Yapılan bu çalışmalar incelendiğinde, bindirme bölgesi uç kısımları soyulma gerilmelerine maruz kalmaktadır. Yapıştırma bağlantıları soyulma gerilmelerinden ziyade kayma gerilmelerine karşı daha dirençlidir. Araştırmacılar tek tesirli bindirme bağlantılarında, bindirme uç bölgelerinde bazı tasarım değişiklikleri yaparak bağlantı dayanımını arttırmayı amaçlamışlardır [13].

Yapıştırıcıların kullanıldığı uygulama alanlarından birisi de mil göbek bağlantılarıdır. Mil ve göbek (dişli çark, kaplin, tekerlek vb.) arasında moment iletimini sağlamak için çeşitli yöntemler kullanılmaktadır. Bu yöntemlerden en çok kullanılanları, kamalı bağlantılar, sıkı geçmeler, konik geçmeler olarak karşımıza çıkmaktadır. Sanayide yoğun bir şekilde kullanılan bu yöntemlerin bazı dejavantajları bilinmektedir. Kamalı bağlantılarda mil ve göbeğe açılan kanallar nedeniyle birleştirme bölgesinde düzgün bir gerilme dağılımı oluşmamakta ve özellikle kama kanallarında oluşan gerilme yığılmaları dayanımı düşürmektedir. Sıkı geçme bağlantılarında ise mil ve göbeğin çok hassas toleranslarda işlenmesi zorunluluğu imalat açısından güçlükler meydana getirmektedir. Konik geçmelerde ise, mil ve göbeğin eş koniklikte işlenmesi imalatı zorlaştırıcı bir işlemdir. Son yıllarda yapıştırıcı teknolojisinin gelişmesiyle birlikte yüksek dayanımlı yapısal yapıştırıcılar endüstride birçok uygulamada kullanılmaktadır. Klasik mil göbek bağlantı yöntemleriyle karşılaştırıldığında, mil ve göbeğe kanal açılmaması, çok hassas toleranslarda işleme zorunluluğu olmaması, yapıştırıcıların mil-göbek bağlantılarında kullanılmasını olumlu yönde etkilemektedir.

Mil-göbek bağlantı tasarımlarında, mümkün olduğu kadar çentik etkisinin en aza indirilmesi, büyük çap değişikliklerinden kaçınılması, kuvvet çizgilerinin ani olarak yön değiştirmesinin önlenmesi, bağlantı dayanımını arttıran önlemlerin başında gelmektedir. Yapıştırma bağlantılarında göbek üzerinde yapılan kademeli geçişler yük taşıma kabiliyetini arttırabilmektedir. Mil-göbek bağlantılarının yapıştırıcıyla yapılması durumunda talaşlı imalat maliyetleri azalırken daha geniş tolerans aralıklarında çalışmak mümkün olabilecektir [4].

Vu Nguyen ve Kedward ( 2001), silindirik eğik alınlı yapıştırma bağlantılarında (scarf joint) bağlantı performansını analitik ve sonlu elemanlar analizleriyle araştırmışlardır. Sonuç olarak eğik alınlı bağlantılarda yapıştırma bölgesinde düz alınlı bağlantılara göre daha düzgün bir gerilme dağılımı oluştuğunu göstermişlerdir [5].

Sekercioğlu vd. (2003), yapıştırıcıyla birleştirilmiş silindirik yapıştırma bağlantılarında, birleştirilen malzemelerin yüzey pürüzlülük değerlerinin bağlantı mukavemetine etkisini deneysel olarak araştırmışlardır. Araştırmacılar yapmış oldukları çalışma sonucunda, S235JR genel yapı çeliği için ideal pürüzlülük değerini $\mathrm{R}_{\mathrm{a}}=1,5-2 \mu \mathrm{m}$ olarak tespit etmişlerdir [6]. 
Pugno ve Carpinteri (2003), eksenel yük altındaki boru yapıştırma bağlantılarında yapıştırıcı tabakasındaki gerilme dağılımını araştırmışlardır. Araştırmacılar yaptıkları gerilme analizi sonucunda, maksimum kayma gerilmelerinin yapıştırma bölgeleri kenarlarında oluştuğunu tespit etmişlerdir [7].

Temiz vd. (2005), film tipi yapıştırıcı kullanarak ürettikleri tek tesirli yapıştırma bağlantılarında, malzeme kalınlığı ve bindirme mesafesi değişiminin bağlantı dayanımına etkisini deneysel ve sayısal olarak araştırmışlardır. Araştırmacılar yaptıkları analizler neticesinde bindirme uçlarındaki soyulma gerilmelerinin hasar oluşumunda etkin rol oynadığını göstermişlerdir [8].

Nemeş vd. (2006), çekme yüküne maruz bırakılmış silindirik yapıştırma bağlantılarında gerilme dağılımını tahmin edebilmek için analitik bir model oluşturmuşlardır. Araştırmacılar oluşturdukları model ile bağlantıdaki geometrik ve malzemelere ait bazı parametrelerin değişiminin etkilerini incelemişlerdir [9].

Zou ve Taheri (2006), burulma yükü uygulanmış boru yapıştırma bağlantılarında, malzeme, boru et kalınlığı, yapıştırıcı tipi gibi faktörlerin etkilerini incelemek için analitik bir model geliştirmişlerdir. Oluşturulan modelde, yapışma bölgesi uç kısımlarındaki gerilme yığılması; bindirme uzunluğu, malzeme kalınlığı, yapıştırıcı özelliği gibi faktörlerin fonksiyonu olarak hesaplanmıştır [10].

Solmaz (2008), farklı bindirme mesafeleri ve uç açılarında, yüksek mukavemetli ve düşük mukavemetli iki farklı dayanımdaki yapıştırıcı kullanarak ürettiği basit bindirme bağlantılarının dayanım özelliklerini çekme zorlaması altında deneylerle ve nümerik tasarımlarla araştırmıştır. Sonuç olarak, düşük mukavemetli yapıştırıcı kullanılarak birleştirilen bağlantıların bindirme uç açısı değişimiyle, yüksek mukavemetli yapıştırıcı kullanılan bağlantılar kadar yük taşıyabileceğini göstermiştir [11].

Esmaeel ve Taheri (2009), kompozit ve alüminyum malzeme kullanarak oluşturdukları boru yapıştırma bağlantılarında, delaminasyon etkisini sonlu elemanlar metoduyla araştırmışlardır. Sonuç olarak, tabaka içi ayrılmaların yapıştırıcı tabakasında gerilme dağılımını etkilediğini belirtmişlerdir [12].

Cognard vd. (2010), çekme yükü uygulanmış silindirik yapıştırma bağlantılarında, bindirme uzunluğu uç bölgelerinin gerilme dağılımına etkilerini lineer elastik gerilme analizleri ile araştırmışlardır. Araştırmacılar yaptıkları çalışma sonucunda kenar geometrilerinin bağlantı mukavemetini etkilediğini, bağlantı kenarlarında yapılacak tasarım değişiklikleri ile bağlantı performansının arttığını tespit etmişlerdir [13].

Lyon (2010), silindirik yapıştırma bağlantılarında ve diğer yapıştırma bağlantılarında kullanılabilecek iki boyutlu, simetrik, lineer elastik bölgede kullanılabilecek sonlu elemanlar modeli geliştirmiştir. Araştırmacı, yaptığı analizler sonucunda bağlantı mukavemetini yapıştırma bölgesi uzunluğu, yapıştırılan malzeme kalınlıkları, yapıştırma bölgesi kenar geometrileri vb. birçok parametrenin etkilediğini belirtmiştir [14].

Solmaz ve Turgut (2011), yaptıkları deneysel ve sayısal çalışmada tek tesirli bindirme bağlantılarında bindirme mesafesi ve bindirme uç açı değişiminin bağlantı dayanımına etkisini araştırmışlardır. Sonuçta, bindirme uzunluğu artışı ve uç açısı artışının bağlantı dayanımını arttırdığını tespit etmişlerdir [15].

Akpınar (2014), çekme yükü etki ettirilmiş tek tesirli bindirme bağlantısı, tek basamaklı bağlantı ve üç basamaklı bağlantı geometrilerinde oluşturduğu yapıştırma bağlantılarının mekanik özelliklerini 
deneysel ve nümerik olarak incelemiştir. Sonuçta, tek tesirli bindirme bağlantılarına göre, tek ve üç basamaklı bağlantılarda bindirme uçlarındaki gerilme yığılmalarının azaldığını belirtmiştir [16].

Pinto vd. (2014), yaptıkları çalışmada, tek tesirli bindirme bağlantılarının bindirme bölgesi uç kısımlarındaki malzeme kalınlığının azaltılması neticesinde, soyulma etkisinin azaldığını ve bunun sonucunda bağlantı dayanımının arttığını deneysel ve sayısal olarak tespit etmişlerdir [17].

Taş (2016), yaptığı çalışmada, farklı mekanik özelliklerdeki yapıştırıcıları kullanarak oluşturduğu konik geçme bağlantılarının döndürme momenti etkisindeki dayanım özelliklerini yaptığı nümerik analizlerle incelemiştir. Araştırmacı yaptığı çalışmada, farklı yapıştırıcı kalınlığı ve konik tepe açılarında tasarladığı yapıştırıcılı konik bağlantıların mekanik özelliklerini yapıştırıcısız konik geçme bağlantılarıyla karşılaştırmıştır. Analizler sonucunda yapıştırıcısız bağlantılarda meydana gelen gerilme değerleri yapıştırıcılı bağlantılara göre daha yüksek değerlerde bulunmuştur [18].

Kumar ve Khan (2016), çekme yükü altındaki silindirik yapıştırma bağlantılarında yapıştırma bölgesinde meydana gelen gerilme dağılımını bir analitik model oluşturarak incelemişlerdir. Daha sonra oluşturdukları analitik modeli doğrulamak amacıyla sonlu elemanlar analizleri yapmışlardır. Yapılan çalışma sonucunda, analitik ve sonlu elemanlar çözümlemelerinin uyumlu olduğunu belirtmiş̧lerdir [19].

Çalık (2016), yaptığı çalışmada tek tesirli bindirme bağlantılarında yapıştırılan malzeme bindirme uçlarındaki şekilsel değişikliklerin, bağlantı mukavemetine etkisini sayısal olarak araştırmıştır. Çalışma neticesinde, yapıştırılan malzemelerde bindirme uçlarındaki şekil değişiklerinin soyulma ve kayma gerilmelerini azaltarak bağlantı mukavemetini arttırdığını belirtmiştir [20].

Yapıştırma bağlantıları ile ilgili yapılan bazı çalışmalarda yapıştırıcı içerisine belirli oranlarda eklenen organik veya inorganik özelliklerdeki nanopartiküllerin bağlantı dayanımlarını önemli oranlarda arttırdığı yapılan çalışmalarda gösterilmiştir [21-24].

Aimmanee vd. (2017), burulma momenti uygulanmış boru yapıştırma bağlantılarında lineer-elastik bölgede geçerli analitik bir model oluşturmuşlardır. Hazırlanan modelin ideal bağlantı şartları için kullanılabilceği belirtilmiştir [25].

Braiek vd. (2018), filament sargı yöntemiyle üretilmiş boruları yapıştırıcı ile birleştirerek oluşturdukları silindirik yapıştırma bağlantılarında bir dizi iç basınç testleri yapmışlardır. Deney sonuçları, yapıştırıcı bölgesinde sızıntı olduğunu göstermiştir. Deney sonuçları ve yapıştırıcının doğrusal olmama davranışı dikkate alınarak bir sonlu eleman modeli geliştirilmiştir. Yapılan çalışmada deneysel ve sayısal sonuçların uyumlu olduğu vurgulanmıştır [26].

Aimmanee vd. (2018), eksenel yük uygulanan boru yapıştırma bağlantılarında daha önceki çalışmalara göre basitleştirilmiş bir matematiksel model geliştirmişlerdir. Yapılan analitik çalışmanın isotropik ve kompozit özellikteki malzemelerle oluşturulan boru yapıştırma bağlantılarında oldukça iyi sonuçlar verdiği belirtilmiştir [27].

Noda vd. (2018), silindirik ve plaka şeklinde tasarlanan alın yapıştırma bağlantılarında çekme yükü altındaki hasar davranışlarını analitik ve sayısal olarak araştırmışlardır. Yapılan çalışmada, tekil gerilme yoğunluğu bölgesinin yapıştırma bağlantı dayanımlarında etkili olduğu belirtilmiştir [28].

Amaro vd. (2019), tek tesirli yapıştırma bağlantılarında, bindirme uç bölgelerinin açılı modellenmesinin dayanıma etkilerini deneysel ve sayısal olarak araştırmışlardır. Deney sonuçlarına göre bindirme uç kısımlarındaki açının azalması dayanımı arttırmıştır. Yapılan deneysel çalışma ile sayısal çalışmanın uyumlu olduğu belirtilmiştir [29]. 
Albiez vd. (2019), çelik boru kullanarak ürettikleri yapıştırma bağlantılarında, boru çapı, bindirme bölgesi uzunluğu, boru et kalınlığı, yapıştırıcı tipi, yapıştırıcı kalınlığı, imalattan kaynaklı merkezleme ve açısal doğrusalsızlık gibi bağlantı parametrelerinin dayanıma etkilerini çekme yükü altında deneysel olarak araştırmışlardır. Çalışma sonucunda, bindirme bölgesi uzunluğunun artması sonucu bağlantı dayanımı artmıştır, ancak artış doğrusal olmamıştır, yapıştırıcı kalınlığının artışı bağlantı dayanımı düşürmüştür, birleştirilen parçalardaki hizalama hatası ve açısal doğrusalsızlıkların dayanıma etkileri az olmuştur, yapıştırıcı tipi ve boru et kalınlığının bağlantı dayanımına etkisi gözlemlenmiştir, yapıştırıcıların çekme ve kayma testleri sonucunda elde edilen dayanım değerlerinin tek başına bağlantı performanslarını belirlemede güvenilir bir yöntem olmayacağı ve bağlantı geometrisinin dayanımı etkilediği vurgulanmıştır. Çalışmanın ikinci kısmında bağlantı dayanımlarını tahmin etmek için analitik bir model geliştirilmiş ve sayısal analizler yapılmıştır [30-31].

Lavalette vd. (2020), çekme yükü uygulanmış alüminyum-kompozit boru yapıştırma bağlantılarında, bindirme bölgesi uzunluğu, iç boru çap1 değişimi, boru et kalınlığı, yapıştırıcı kalınlığı ve bindirme bölgesi boru uç geometrisi değişiminin bağlantı dayanımına etkilerini analitik ve deneysel olarak incelemişlerdir. Yapılan parametrik çalışma sonucunda, bindirme uzunluğu ve iç boru çapı artışının bağlantı dayanımını önemli oranda etkilediği belirtilmiştir. Bindirme uzunluğu artışının dayanıma etkisi belirli bir uzunluktan sonra gözlemlenmemiştir. Boru et kalınlığı ve boru uç geometrisi değişikliği yapıştırıcı tabakasındaki gerilme dağılımını etkilemiştir [32].

Rudawska vd. (2020), alın birleştirme şeklinde imal edilmiş silindirik yapıştırma bağlantılarında yaşlandırma uygulamasının bağlantıların mekanik özelliklerine etkilerini anlamak için deneysel çalışmalar yapmışlardır. Yaşlandırma işlemleri üç farklı ortamda (mineralli su, demineralize edilmiş su, çeşme suyu) 3 ve 6 ay sürelerinde uygulanmıştır. Yaşlandırma işlemleri sonucunda yapıştırma bağlantılarına çekme testleri uygulanmıştır. Deneyler sonucunda daha uzun süre yaşlandırma işlemi uygulanan numunelerin dayanımları düşmüştür. Kısa süreli çalışmalarda çelik borular kullanılarak oluşturulan alın yapıştırma bağlantılarının iyi sonuçlar verdiği vurgulanmış ve diğer bağlantı yöntemlerine göre maliyetinin düşük olmasından dolayı kullanılabileceği belirtilmiştir [33].

Araştırmacılar tarafından tek tesirli ve silindirik yapıştırma bağlantılarında yapılan çalışmalar incelendiğinde, bindirme uç geometrilerinde yapılan değişikliklerin bağlantı performansını etkilediği görülmektedir. Silindirik yapıştırma bağlantılarıyla ilgili yapılan çalışmalarda genellikle bağlantıların çekme yükü altındaki performansları araştırılırken burulma yükü uygulanarak yapılan çalışmalar nispeten sınırlı olmuştur. Bu çalışmada ilk olarak bir silindirik yapıştırma bağlantısı olarak tasarlanan mil-göbek bağlantı modelinin burulma momenti altındaki lineer elastik gerilme analizi ANSYS APDL programı kullanılarak yapılmıştır. Daha sonra, oluşturulan yeni mil-göbek bağlantı modellerinde göbek kenarlarında yapılan tasarım değişikliklerinin bağlantı performansına etkileri yapılan gerilme ve hasar analizleriyle araştırılmıştır. Oluşturulan silindirik yapıştırma bağlantısı modellerine, burulma momenti uygulanmasının sebebi makinelerde mil-göbek bağlantılarının moment aktarımında kullanılmasıdır. $\mathrm{Bu}$ çalışmanın amacı yapıştırıcıyla birleştirilmiş ve burulma momenti uygulanmış mil göbek bağlantılarında hasarın oluşumunda etkin olan gerilmeleri tespit etmek ve bağlantı performansını arttırabilmek için göbek kısmında yapılabilecek bazı tasarım değişikliklerinin etkilerini irdelemektir.

\section{Materyal ve Metot}

Mil-göbek bağlantısı referans modeli, Şekil 1'de gösterilen boyutlara göre ANSYS sonlu elemanlar analiz programı kullanılarak oluşturulmuştur. Buna göre mil çapı $5 \mathrm{~mm}$, göbek dış çap1 $10 \mathrm{~mm}$, yapıştırıcı kalınlığı $0.25 \mathrm{~mm}$, bağlantı genişliği $10 \mathrm{~mm}$ olarak alınmıştır. 

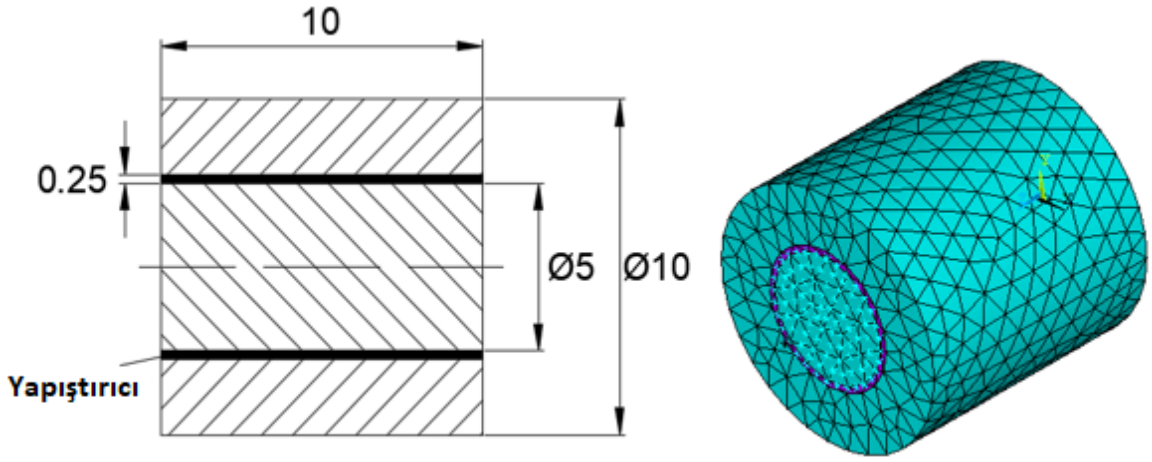

Şekil 1. Referans model

Şekil 2 ve Şekil 3'te göbek kenar tasarımı farklı modellerin teknik resimleri ve ANSYS APDL' de oluşturulmuş üç boyutlu görünüşleri verilmiştir. Şekil 2'de gösterilen modellerde göbek kenar çap1 Model-1'de 9 mm'ye, Model-2'de 8 mm'ye, Model-3'te 7 mm'ye, Model-4'te $6 \mathrm{~mm}$ düşürülmüştür. Çap düşürme işlemi göbek genişliğinin yarısına kadar gerçekleştirilmiştir. Göbekteki çentik etkisini azaltabilmek amacıyla oluşturulan modellerde göbek dış çapı ve göbek kenar çap1 arasında Model-1'de 0.5 mm, Model-2'de $1 \mathrm{~mm}$, Model 3'te $1.5 \mathrm{~mm}$, Model-4'te $2 \mathrm{~mm}$ radyüsler oluşturulmuştur.

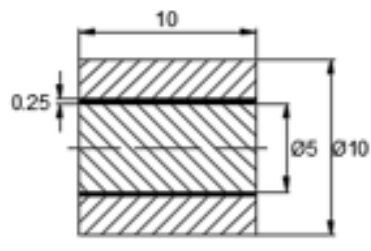

Referans model

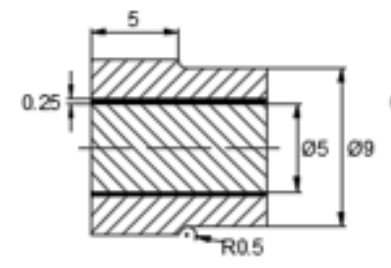

Model-1

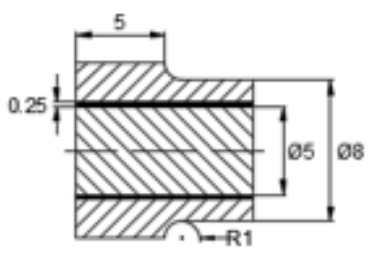

Model-2

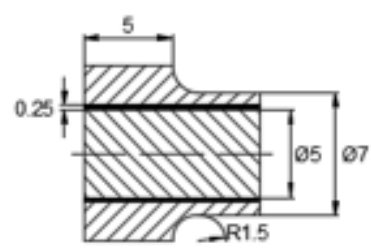

Model-3

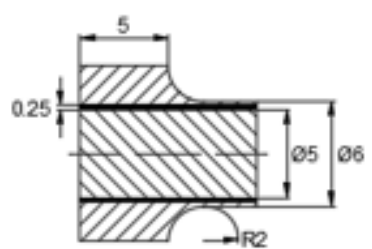

Model-4

Şekil 2. Göbek kenar çapı farklı modeller

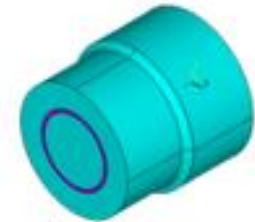

Model-1

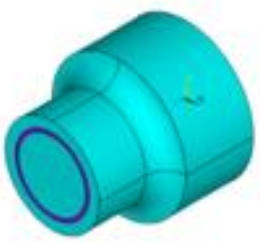

Model-3
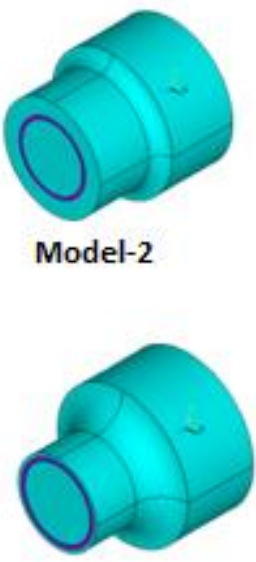

Model-4

Şekil 3. Modellerin üç boyutlu görünüşleri 
Oluşturulan bütün modellerde yapıştırıcı olarak DP460 epoksi yapıştırıcı ve yapıştırılan malzeme olarak ise St37 genel yapı çeliği kullanılmıştır. DP460 epoksi yapıştırıcı ve St37 genel yapı çeliğine ait Tablo 1'de verilen mekanik özellikler programa tanımlanmıştır.

Tablo 1. DP460 ve St37 mekanik özellikleri [34-35].

\begin{tabular}{lcc}
\hline \multirow{2}{*}{\multicolumn{1}{c}{ Özellikler }} & \multicolumn{2}{c}{ Malzemeler } \\
\cline { 2 - 3 } & St37 & DP460 \\
\hline Elastisite modülü $(\mathrm{MPa})$ & 200000 & 1984 \\
Poisson oranı & 0.3 & 0.38 \\
Akma dayanımı $(\mathrm{MPa})$ & 235 & 38.4 \\
Çekme dayanımı $(\mathrm{MPa})$ & 375 & 44.6 \\
\hline
\end{tabular}

Oluşturulan modelleri elemanlara ayırma işlemi yapılan analizin doğruluğunu etkileyen çok önemli bir așamadır. Eleman boyutu azaldıkça genellikle șekil değiștirme miktarları artmaktadır. Bundan dolayı şekil değiştirme miktarlarının stabil olduğu eleman boyutunun tespit edilmesi gerekmektedir. Yapılan yakınsama işlemleri sonucunda eleman boyutu bütün modellerde 1 olarak alındı. Sonlu elemanlar modellemesinde, Şekil 4'te gösterilen, 3 serbestlik dereceli ve 20 düğüm noktalı solid 186 elemanı kullanılmıştır.

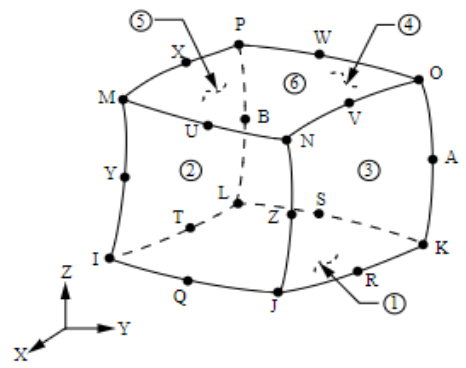

Şekil 4. Solid 186 eleman [36].

Probleme ait sınır şartları Şekil 5' te gösterildiği gibi programa tanımlanmıştır. Buna göre, göbeğin bir ucu tüm yönlerde mesnetlenmiştir. Mile moment uygulayabilmek için diğer taraftaki mil kesit alanı dış tarafta tanımlanan bir düğüm noktası ile kontak oluşturularak bağlanmıştır. Böylece dış taraftaki düğüm noktasına z yönünde $1000 \mathrm{Nmm}$ moment uygulanmıştır. Dügüum noktası ile mil yüzey alanı arasında oluşturulan kontak ilişkisi düğüm noktasına uygulanan momenti mile aktarmıştır. Bu şekilde mil-göbek bağlantısı burulmaya zorlanmıştır. Oluşsturulan bütün modellere $1000 \mathrm{Nmm}$ burulma momenti uygulanmıştır.
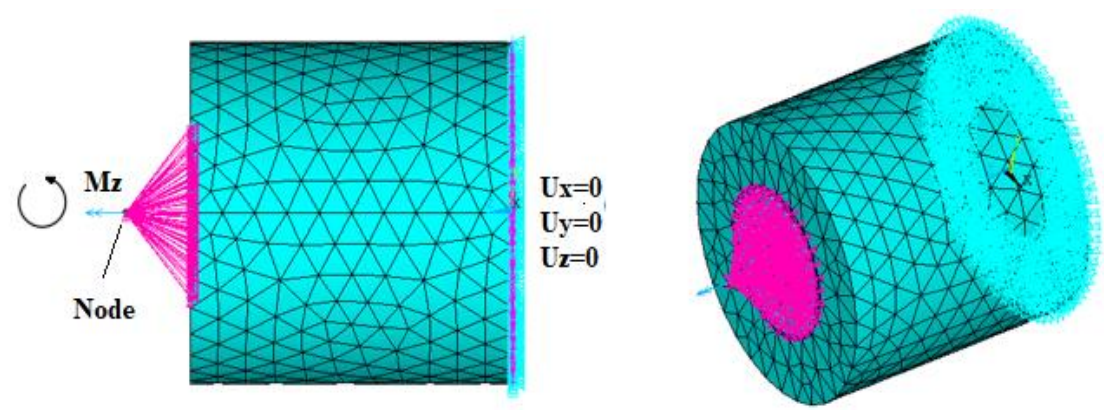

Şekil 5. Mil-göbek bağlantısı sınır şartları

Yapıştırma bağlantılarının sayısal hasar yüklerini tespit etmek için ANSYS APDL programı içerisinde tanımlı olan hasar kriterleri içerisinde yer alan maksimum gerilme (kayma ve eşdeğer gerilme) teorisi kullanılmıştır. Bu teoriye göre, oluşan gerilmeler lokal eksenlerde çekme, basma ve kayma gerilmesi bileşenlerine ayrılmaktadır. Bu gerilme bileşenlerinden birisi normal veya kayma dayanımını aşarsa malzemede hasarın oluştuğu kabul edilmektedir. St37 için çeki ve bası durumları 
için normal gerilme dayanımı +- $235 \mathrm{MPa}$, kayma gerilmesi dayanım değeri 117,5 MPa, DP460 epoksi yapıştırıcı için çeki ve bası durumları için normal gerilme dayanım değerleri $+-38,4 \mathrm{MPa}$, kayma gerilmesi dayanım değeri $24 \mathrm{MPa}$ [23] olarak programa tanımlanmıştır.

\section{Bulgular ve Tartışma}

Bu çalışmada, başlangıçta referans mil-göbek bağlantı modelinin burulma momenti altındaki lineer elastik gerilme analizi ANSYS APDL programı kullanılarak yapılmıştır. Şekil 6 ve Şekil 7'de sırasıyla referans model, mil, göbek ve yapıştırıcı tabakasında oluşan eş değer gerilme dağılımları $\left(\sigma_{\text {eqv }}\right)$ ve $\tau_{\mathrm{xy}}$ kayma gerilme dağılımları gösterilmiştir.
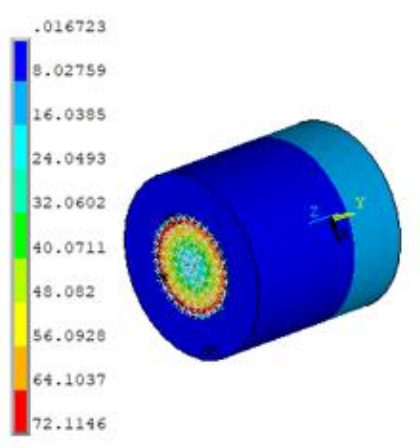

a)

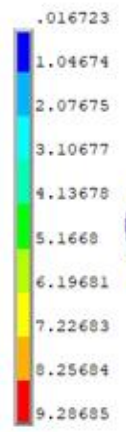

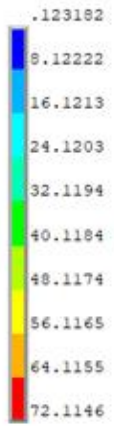

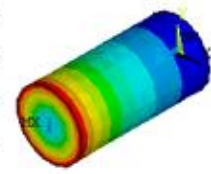

b)

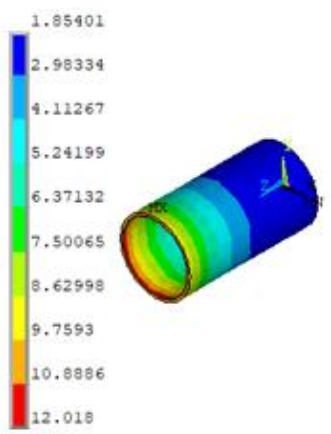

d)

Şekil 6. Referans model eş değer gerilme dağılımları (a-Mil-göbek, b-mil, c-göbek, d-yapıştırıcı)

Şekil 8'de gösterilen yapıştırıcı tabakasındaki A-B hattı için $\tau_{\mathrm{xy}}$ kayma ve eşdeğer gerilme $\left(\sigma_{\text {eqv }}\right)$ dağılımları Şekil 9'da gösterilmiştir. Yapıştırma bağlantılarında mukavemet açısından kritik bölge yapıştırıcı ve yapıştırılan malzeme ara yüzeyidir. İki ayrı özellikteki malzemenin birleşim bölgesi olan bu bölgede oluşan gerilmeler genellikle hasar başlangıcının sebebidir.

Yapıştırıcı tabakası A-B hattındaki gerilme dağılımları incelendiğinde, $\sigma_{\mathrm{x}}, \sigma_{\mathrm{y}}, \sigma_{\mathrm{z}}$ normal gerilmeleri ve $\tau_{\mathrm{yz}}, \tau_{\mathrm{xz}}$ kayma gerilmeleri oldukça küçük değerlerde çıkmıştır. $\sigma_{\text {eqv }}$ eşdeğer gerilmesi ise $\tau_{\mathrm{xy}}$ kayma gerilmesine paralel olarak Şekil 9'da gösterildiği gibi hesaplanmıştır. Şekil 6.d, Şekil 7.d ve Şekil 9'da gösterilen gerilme dağılımları incelendiğinde moment uygulanan taraftaki bindirme uzunluğu uç bölgelerinde $\tau_{\mathrm{xy}}$ ve $\sigma_{\text {eqv }}$ gerilmeleri maksimum değerleri almakta ve diğer kenara doğru azalmaktadır. Bu durumda mil-göbek bağlantısı hasarının gerilme değerlerinin en yüksek olduğu göbek kenarından başlaması beklenmektedir.

Literatür incelendiğinde, mil-göbek bağlantılarında, büyük çap değişikliklerinden kaçınılması, kuvvet çizgilerinin ani olarak yön değiştirmesinin önlenmesi, bağlantı dayanımını arttıran önlemlerin başında gelmektedir. Yapıştırma bağlantılarında göbek üzerinde yapılan kademeli geçişler yük taşıma kabiliyetini arttırabilmektedir [4]. Buna göre bu çalışmada referans olarak 
alınan ve gerilme analizi yapılan mil-göbek bağlantısının yük taşıma kabiliyetini arttırabilmek için, referans modele göre maksimum gerilmenin oluştuğu göbek kenarlarında kademeli geçişler yapılarak oluşturulan modeller üzerinde gerilme ve hasar analizleri yapılmıştır. Oluşturulan modellerin boyutları Şekil 2'de verilmiştir.

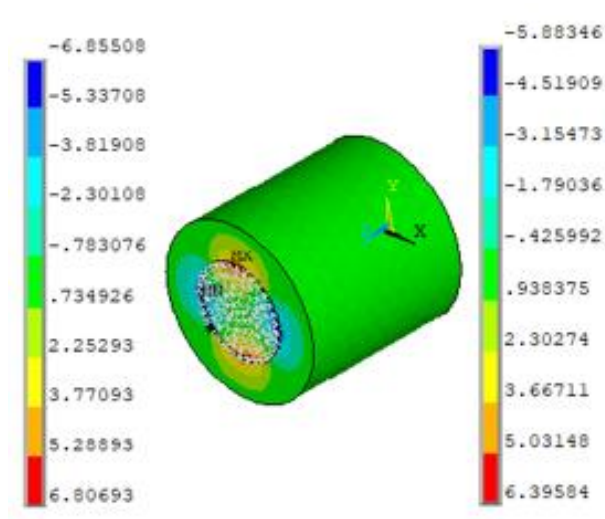

a)

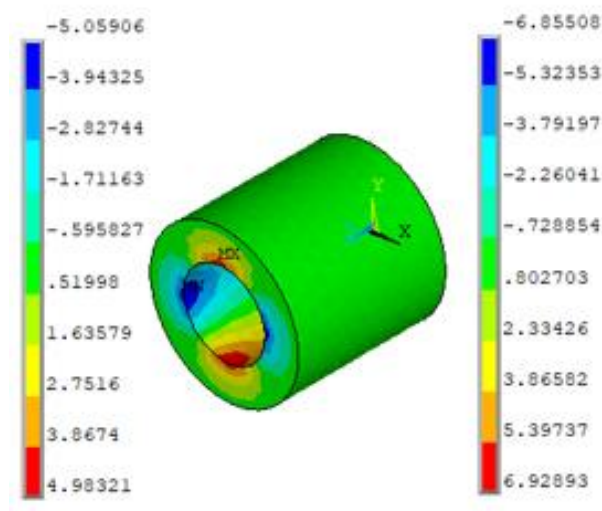

c)

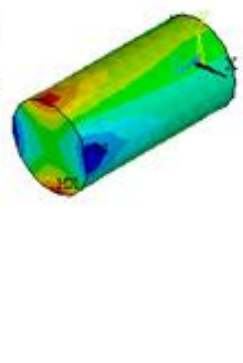

b)

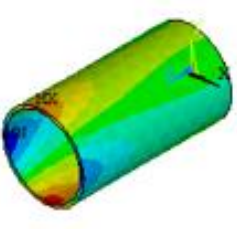

d)

Şekil 7. Referans model $\tau_{\mathrm{xy}}$ kayma gerilme dağılımları (a-Mil-göbek, b-mil, c-göbek, d-yapıştırıcı)

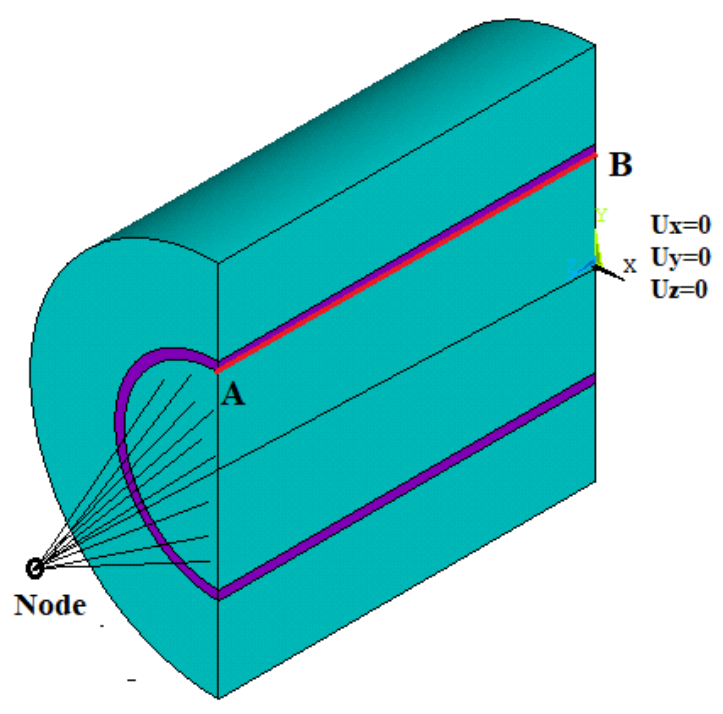

Şekil 8. Yapıştırıcı tabakasındaki A-B hattı 


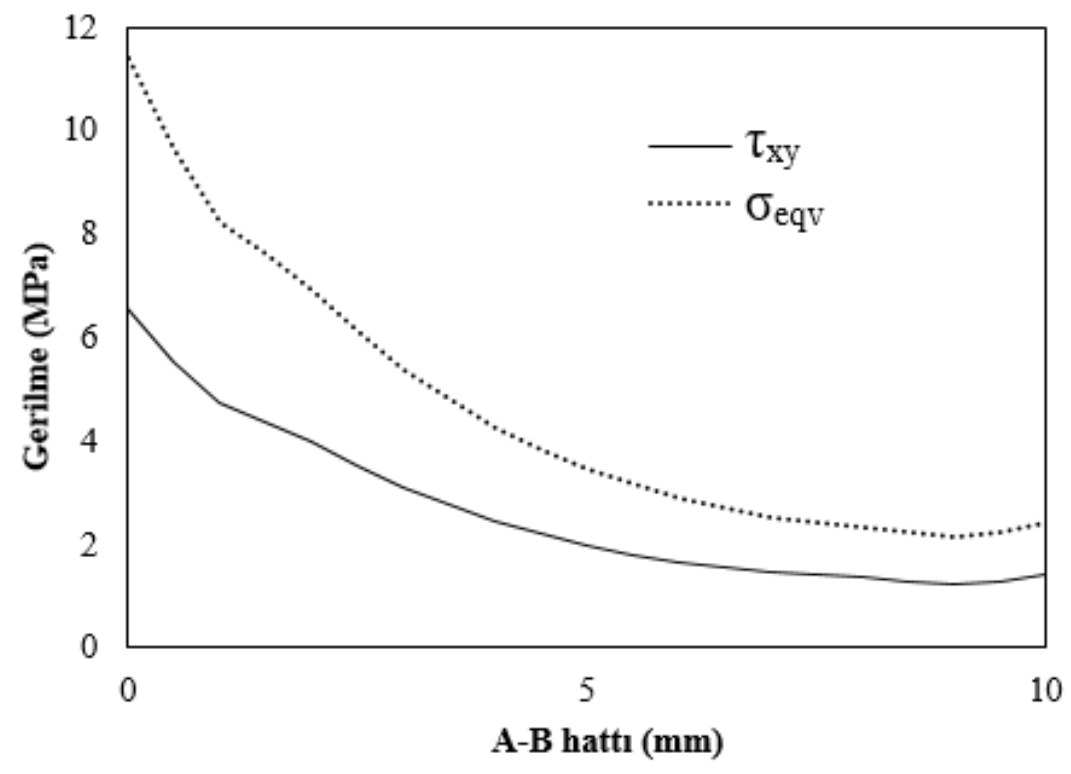

Şekil 9. Yapıştıııcı tabakasındaki A-B hattı gerilme dağılımı.

Şekil 10'da gösterilen grafikte bütün modellerdeki yapıştırıcı tabakasındaki A-B hattı boyunca elde edilen eş değer gerilme dağılımları gösterilmiştir. Şekil 10'da gösterilen grafik incelendiğinde, oluşturulan modellerdeki maksimum eşdeğer gerilme değerleri referans modele göre daha düşük çıkmıştır. Referans modeldeki maksimum eşdeğer gerilme 11.3 MPa olarak bulunurken, Model-1, Model-2, Model-3 ve Model-4'te sırasiyla, 11.2 MPa, 11 MPa, 10.5 MPa ve 8.7 MPa bulunmuştur. Yapıştırıcı tabakasındaki eş değer gerilmelerin azalması sonucu, oluşturulan modellerin hasar momentleri artmıştır. En belirgin hasar momenti artış değeri Model-4'te \%30 olarak hesaplanmıştır (Tablo 2).

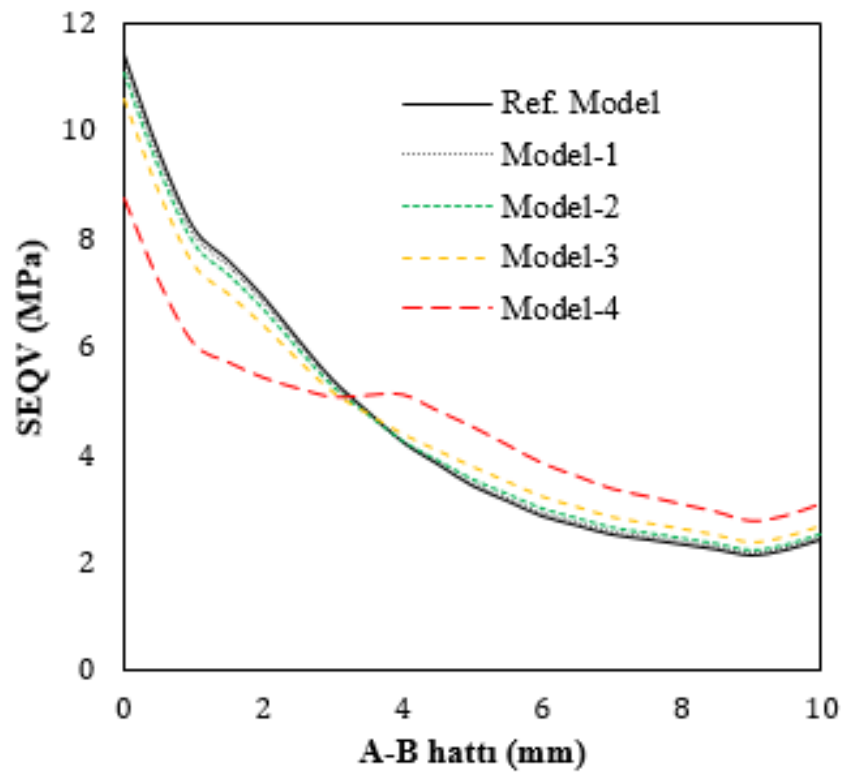

Şekil 10. Modellerde A-B hattı eşdeğer gerilme dağılımı

Tablo 2'de bütün modellere ait hasar indeksi ve hasar moment değerleri gösterilmiştir. Hasar indeksi nümerik hasar yüklerini tespit edebilmek için kullanılan basit bir sayıdır. Sonlu elemanlar hasar momentleri, mil-göbek bağlantılarına uygulanan momentlerin hasar indekslerine bölünmesiyle bulunmuş̧ur. Oluşturulan mil-göbek bağlantı modellerinde göbek kenar bölgesinde yapılan çap düşümü yapıştırma tabakası uç bölgesindeki gerilme yığılmalarını azaltmıştır. Göbek 
kenar bölgesindeki et kalınlığı, yapıştırıcı kalınlığına yaklaştıkça göbek kenarındaki gerilme yığglması azalmıștır. Bu durum genel makine tasarımında, birleștirilecek parçaların mümkün olduğunca eşit kalınlıkta olması ilkesiyle örtüşmektedir. Ancak göbek kenarında çap düşümü yapılmasının mil ve göbek üzerindeki etkilerinin de irdelenmesi gerekmektedir. Referans modeldeki mil üzerinde görülen gerilme dağılımları diğer modellerdeki mil üzerinde elde edilen gerilme dağılımları ile karşılaştırıldığında herhangi bir değişiklik görülmemiştir. Yapılan tasarım değişiklikleri, göbek üzerinde oluşan gerilme dağılımını oldukça etkilemiştir.

Tablo 2. Yapıştırıcı tabakasında hasar momentleri

\begin{tabular}{cccc}
\hline Modeller & Uygulanan moment $(\mathbf{N m m})$ & Hasar indeksi & Hasar momenti $(\mathbf{N m m})$ \\
\hline Ref. Model & 1000 & 0.263 & 3802.2 \\
Model-1 & 1000 & 0.260 & 3846.1 \\
Model-2 & 1000 & 0.255 & 3921.5 \\
Model-3 & 1000 & 0.244 & 4098.3 \\
Model-4 & 1000 & 0.201 & 4975.1 \\
\hline
\end{tabular}

Tablo 3'te gösterildiği gibi, referans modelde hasar momenti $22222.2 \mathrm{Nmm}$ olarak bulunurken, Model-1, Model-2, Model-3 ve Model-4'te sirasiyla, 17857.1 Nmm, 13333.3 Nmm, 8478.5 Nmm ve $3496.5 \mathrm{Nmm}$ olarak hesaplanmıştır. Tablo 2 ve Tablo 4'teki sonuçlar birlikte değerlendirildiğinde, göbek ve yapıştırıcı tabakasındaki hasar momentleri dikkate alındığında Model-3 tasarımının bu çalışma şartlarında ideal tasarım olduğu sonucuna varılmıştır. Çünkü Model-3'te göbek için hasar momenti $8478.5 \mathrm{Nmm}$, yapıştırıcı için ise 4098.3 Nmm'dir. Bu durumda, referans modele göre Model-3'te göbek için hasar mukavemeti düşmesine rağmen, yapıştırıcının hasar mukavemeti daha düşük olmaktadır.

Tablo 3. Göbekteki sonlu elemanlar hasar momentleri

\begin{tabular}{lccc}
\hline Modeller & Uygulanan moment $(\mathbf{N m m})$ & Hasar indeksi & Hasar momenti $(\mathbf{N m m})$ \\
\hline Ref. Model & 1000 & 0.045 & 22222.2 \\
Model-1 & 1000 & 0.056 & 17857.1 \\
Model-2 & 1000 & 0.075 & 13333.3 \\
Model-3 & 1000 & 0.118 & 8478.5 \\
Model-4 & 1000 & 0.286 & 3496.5 \\
\hline
\end{tabular}

\section{Sonuçlar}

Yapılan bu sayısal çalışmada; başlangıçta, silindirik yapıştırma bağlantısı olarak tasarlanan milgöbek bağlantı modelinin burulma momenti altındaki lineer elastik gerilme analizi yapılmış ve kritik bölge olan yapıştırıcı tabakasındaki gerilme dağılımı incelenmiştir. Daha sonra, oluşturulan yeni mil-göbek bağlantı modellerinde göbek kenarlarında yapılan tasarım değişikliklerinin bağlantı performansına etkileri yapılan gerilme ve hasar analizleriyle araştırılmıştır. Çalışmadan elde edilen sonuçlar aşağıda verilmiştir.

Yapıştırıcıyla birleştirilmiş mil-göbek bağlantısında mile uygulanan burulma momentinin etkisiyle, yapıştırıcı tabakasında oluşan gerilmeler incelendiğinde, hasar oluşumunda etkin gerilmelerin $\tau_{\mathrm{xy}}$ kayma gerilmesi ve $\sigma_{\text {eqv }}$ eşdeğer gerilmeleri olduğu çok net bir şekilde görülmüştür. 
Oluşturulan mil-göbek bağlantı modellerinde, yapıştırıcı tabakası dikkate alındığında, moment uygulanan taraftaki bindirme uzunluğu uç bölgelerinde $\tau_{\mathrm{xy}}$ ve $\sigma_{\text {eqv }}$ gerilmeleri maksimum değerleri almaktadır ve bütün gerilme değerleri diğer kenara doğru azalmaktadır. Bu durumda mil-göbek bağlantısı hasarının gerilme değerlerinin en yüksek olduğu göbek kenarından başlaması beklenmektedir.

Yapıştırıcı tabakasında, oluşturulan modellerdeki maksimum eşdeğer gerilme değerleri referans model ile kıyaslandığında daha düşük hesaplanmıştır. Referans modeldeki maksimum eşdeğer gerilme 11.3 MPa olarak bulunurken, Model-1, Model-2, Model-3 ve Model-4'te sirasiyla, 11.2 $\mathrm{MPa}, 11 \mathrm{MPa}, 10.5 \mathrm{MPa}$ ve $8.7 \mathrm{MPa}$ olarak hesaplanmıştır. Elde edilen bu gerilme değerleri bütün modellere $1000 \mathrm{Nmm}$ moment uygulandığı durumdaki gerilme değerleridir. Yapıştırıcı tabakasındaki eş değer gerilmelerin azalması sonucu, oluşturulan modellerin hasar momentleri artmıştır. En belirgin hasar momenti artış değeri Model-4'te yaklaşık olarak \% 30 olarak hesaplanmıştır.

Oluşturulan mil-göbek bağlantı modellerinde, göbek kenar bölgesinde yapılan çap düşümü, yapıştırma tabakası uç bölgesindeki gerilme yığılmalarını azaltmıştır. Göbek kenar bölgesindeki et kalınlığı, yapıştırıcı kalınlığına yaklaştıkça göbek kenarındaki gerilme yığılması azalmıştır.

Referans modeldeki mil üzerinde görülen gerilme dağılımları diğer modellerdeki mil üzerinde oluşan gerilme değerleri ile karşılaştırıldığında herhangi bir değişiklik görülmemiştir.

Yapılan tasarım değişiklikleri, göbek üzerinde oluşan gerilme dağılımını oldukça etkilemiştir. Referans modelde hasar momenti 22222.2 Nmm olarak bulunurken, Model-1, Model-2, Model-3 ve Model-4'te sirasiyla, $17857.1 \mathrm{Nmm}, 13333.3 \mathrm{Nmm}, 8478.5 \mathrm{Nmm}$ ve $3496.5 \mathrm{Nmm}$ olarak hesaplanmıştır.

Göbek ve yapıştırıcı tabakasındaki hasar momentleri dikkate alındığında Model-3 tasarımının bu çalışma şartlarında ideal tasarım olduğu sonucuna varılmıştır. Model-3 tasarımında yapıştırıcı tabakasındaki mukavemet artış oranı yaklaşık olarak \% 8 olarak hesaplanmıştır.

\section{Kaynaklar}

[1]. Durmuş, M., Akpinar, S., The experimental and numerical analysis of the adhesively bonded three step-lap joints with different step lengths, Theoretical and Applied Fracture Mechanics, 2020, 105, 102427.

[2]. Bayramoglu, S., Demir, K., Akpinar, S., Investigation of internal step and metal part reinforcement on joint strength in the adhesively bonded joint: Experimental and numerical analysis, Theoretical and Applied Fracture Mechanics, 2020, 108, 102613.

[3]. Akpinar, S., Ozel, A., Experimental and numerical determination of the thermal cycle performance of joints obtained with nanostructure-doped nanocomposite adhesives, Composites Part B, 2019, 174, 106959.

[4]. Şekercioğlu, T., Makine Elemanları Hesap Şekillendirme, Birsen yayın evi, İstanbul, Türkiye, 96-97, 2018.

[5]. Nguyen V., Kedward T., Non-linear modeling of tubular adhesive scarf joints loaded in tension, The Journal of Adhesion, 2001, 76(3), 265-295.

[6]. Şekercioğlu, T., Rende, H., Gülsöz, A., Meran, C., The effects of surface roughness on the strength of adhesively bonded cylindrical components, Journal of Materials Processing Technology, 2003, 142, 82-86.

[7]. Pungo, N., Carpinteri, A., Tubular adhesive joints under axial load, Journal of Applied Mechanics, 2003, 76(6), 832-839. 
[8]. Temiz, Ş., Özel, A., Aydın, M.D., The effect of adherend thickness on the failure of adhesively bonded single lap joints, J Adhes Sci Technol, 2005, 19(8), 705-718.

[9]. Nemes, O., Lachaud, F., Mojtabi, A., Contribution to the study of cylindrical adhesive joining, International Journal of Adhesion \& Adhesives, 2006, 26, 474-480.

[10]. Zou, G.P., Taheri, F., Stress analysis of adhesively bonded sandwich pipe joints subjected to torsional loading, International Journal of Solids and Structures, 2006, 43(20), 5953-5968.

[11]. Solmaz, M.Y., Yapıştırıcı ile birleştirilmiş bağlantıların mekanik analiz ve tasarımları, Doktora Tezi, Fırat Üniversitesi, Fen Bilimleri Enstitüsü, Elazı̆̆ 2008.

[12]. Esmaeel, R.A., Taheri, F., Stress analysis of tubular adhesive joints with delaminated adherend, Journal of Adhesion Science and Technology, 2009, 23, 1827-1844.

[13]. Cognard, J.Y., Devaux, H., Sohier, L., Numerical analysis and optimisation of cylindrical adhesive joints under tensile loads, International Journal of Adhesion \& Adhesives, 2010, 30, 706-719.

[14]. Lyon, P.E., Axisymmetric finite element modeling for the design and analysis of cylindrical adhesive joints based on dimensional stability, Master of Science, Utah State University, Logan, Utah, 2010.

[15]. Solmaz, M.Y., Turgut, A., An experimental and numerical study on the effects of taper angles and overlap length on the failure and stress distribution of adhesively bonded single lap joints, Math Comput Appl, 2011, 16, 159-170.

[16]. Akpinar S., The strength of the adhesively bonded step-lap joints for different step numbers, Composites Part B, 2014, 67, 170-178.

[17]. Pinto, A.M.G., Ribeiro, N.F.Q.R., Campilho, R.S.D.G., Mendes, I.R., Effect of Adherend Recessing on the Tensile Strength of Single Lap Joints, The Journal of Adhesion, 2014, 90, 649-666.

[18]. Taş, B., Yapıştırıcı ile birleştirilmiş konik geçmeli bağlantıların burulma momenti altındaki performansları, Yüksek Lisans Tezi, Fırat Üniversitesi, Fen Bilimleri Enstitüsü, Elazı̆̆, 2016.

[19]. Kumar, S., Khan, M.A., An elastic solution for adhesive stresses in multi-material cylindrical joints, International Journal of Adhesion \& Adhesives, 2016, 64, 142-152.

[20]. Çalık, A., Effect of adherend shape on stress concentration reduction of adhesively bonded single lap joint, Engineering Review, 2016, 36, 29-34.

[21]. Çakır, M., Kınay, D., Nano-Silika Parçacıklarının Al-GFRP Yapıştırma Bağlantılarının Kayma Dayanımına Etkisi, El-Cezeri Journal of Science and Engineering, 2018, 5(2), 625618.

[22]. Ulus, H., Kaybal, H., Demir, O., Senyurt, M., Tatar, A., Avcı, A., Tek Taraflı Bindirme Bağlantısıyla Birleştirilen Tabakalı Kompozitlerin Yapıştırma Performansının NanoMontmorillonit Modifiyeli Epoksi Kullanılarak İyileştirilmesi, El-Cezeri Journal of Science and Engineering, 2018, 5(1), 167-163.

[23]. Gultekin, K., Akpinar, S., Gürses, A., Eroglu, Z., Cam, S., Akbulut, H., Keskin, Z., Özel, A., The effects of graphene nanostructure reinforcement on the adhesive method and the graphene reinforcement ratio on the failure load in adhesively bonded joints, Composites Part B: Engineering, 2016, 67,170-178.

[24]. Akpinar, I.A, Gultekin, K., Akpinar, S., Akbulut, H., Özel, A., Experimental analysis on the single-lap joints bonded by a nanocomposite adhesives which obtained by adding nanostructures, Composites Part B: Engineering, 2017, 110, 420-428.

[25]. Aimmanee, S., Hongpimolmas, P., Stress analysis of adhesive-bonded tubular-coupler joints with optimum variable-stiffness composite adherend under torsion, Composite Structures, 2017, 164, 76-89.

[26]. Braiek, S., Ben Khalifa, A., Zitoune R., Zidi M., Experimental and numerical investigation of adhesively bonded $\pm 55^{\circ}$ filament wound tubular specimens under internal pressure, Engineering Fracture Mechanics, 2018, 199, 461-475. 
[27]. Aimmanee, S., Hongpimolmas, P., Ruangjirakit, K., Simplified analytical model for adhesivebonded tubular joints with isotropic and composite adherends subjected to tension, International Journal of Adhesion and Adhesives, 2018, 86, 59-72.

[28]. Noda, N.A., Ren, F., Takaki, R., Wang, Z., Oda, K., Miyazaki, T., Sano, Y., Intensity of singular stress field over the entire bond line thickness range useful for evaluating the adhesive strength for plate and cylinder butt joints, International Journal of Adhesion and Adhesives, 2018, 85, 234-250.

[29]. Amaro, A.M., Neto, M.A., Loureiro, A., Reis, P.N.B., Taper's angle influence on the structural integrity of single-lap bonded joints, Theoretical and Applied Fracture Mechanics, 2018, 96, 231-246.

[30]. Albiez, M., Vallée, T., Fricke, H., Ummenhofer, T., Adhesively bonded steel tubes Part I: Experimental investigations, International Journal of Adhesion and Adhesives, 2010, 90, 199210.

[31]. Albiez, M., Vallée, T., Ummenhofer, T., Adhesively bonded steel tubes - Part II: Numerical modelling and strength prediction, International Journal of Adhesion and Adhesives, 2019, 90, 211-224.

[32]. Lavalette, N.P, Bergsma, O.K., Zarouchas, D., Benedictus, R., Influence of geometrical parameters on the strength of Hybrid CFRP-aluminium tubular adhesive joints, Composite Structures, 2020, 240, 112077.

[33]. Rudawska, A., Abdel Wahab, M., Müller, M., Effect of ageing process on mechanical properties of adhesive tubular butt joints in aqueous environment, International Journal of Adhesion and Adhesives, 2020, 96, 102466.

[34]. Malag, L., Kukielka, L., Hybrid method to determinate the states of deformation and stress in material during the tensile test, Proc. Appl. Math. Mech., 2007, 7, 2090025-2090026.

[35]. Aydın, M.D., Akpınar, S., Özel, A., Erdoğan, S., Kayma yüküne maruz yapıştırma bağlantılarından yapısal yapıştırıcıların mekanik özelliklerinin belirlenmesi, Mühendis ve Makine, 2015, 56(668), 48-55.

[36]. https://ansyshelp.ansys.com, Erişim tarihi Nisan 1, 2020. 